\title{
The application of nonsense-mediated mRNA decay inhibition to the identification of breast cancer susceptibility genes
}

\author{
Julie K Johnson ${ }^{1,2,5^{*}}$, Nic Waddell ${ }^{3}$, kConFab Investigators $^{4}$ and Georgia Chenevix-Trench ${ }^{1}$
}

\begin{abstract}
Background: Identification of novel, highly penetrant, breast cancer susceptibility genes will require the application of additional strategies beyond that of traditional linkage and candidate gene approaches. Approximately one-third of inherited genetic diseases, including breast cancer susceptibility, are caused by frameshift or nonsense mutations that truncate the protein product [1]. Transcripts harbouring premature termination codons are selectively and rapidly degraded by the nonsense-mediated mRNA decay (NMD) pathway. Blocking the NMD pathway in any given cell will stabilise these mutant transcripts, which can then be detected using gene expression microarrays. This technique, known as gene identification by nonsense-mediated mRNA decay inhibition (GINI), has proved successful in identifying sporadic nonsense mutations involved in many different cancer types. However, the approach has not yet been applied to identify germline mutations involved in breast cancer. We therefore attempted to use GINI on lymphoblastoid cell lines (LCLs) from multiple-case, non- BRCA1/2 breast cancer families in order to identify additional high-risk breast cancer susceptibility genes.

Methods: We applied GINI to a total of 24 LCLs, established from breast-cancer affected and unaffected women from three multiple-case non-BRCA1/2 breast cancer families. We then used Illumina gene expression microarrays to identify transcripts stabilised by the NMD inhibition.

Results: The expression profiling identified a total of eight candidate genes from these three families. One gene, PPARGC1A, was a candidate in two separate families. We performed semi-quantitative real-time reverse transcriptase PCR of all candidate genes but only PPARGC1A showed successful validation by being stabilised in individuals with breast cancer but not in many unaffected members of the same family. Sanger sequencing of all coding and splice site regions of PPARGC1A did not reveal any protein truncating mutations. Haplotype analysis using short tandem repeat microsatellite markers did not indicate the presence of a haplotype around PPARGC1A which segregated with disease in the family.
\end{abstract}

Conclusions: The application of the GINI method to LCLs to identify transcripts harbouring germline truncating mutations is challenging due to a number of factors related to cell type, microarray sensitivity and variations in NMD efficiency.

\footnotetext{
* Correspondence: Julie.Johnson@qimr.edu.au

${ }^{1}$ Queensland Institute of Medical Research, Brisbane, Australia

${ }^{2}$ School of Medicine, University of Queensland, Brisbane, Australia

Full list of author information is available at the end of the article
} 


\section{Background}

Germline mutations in either one of the two major breast cancer tumour suppressor genes, $B R C A 1$ or $B R C A 2$, confer a $60-85 \%$ lifetime risk of breast cancer but explain only around $20 \%$ of the breast cancer cases that have a family history of the disease [2-8]. However, almost $70 \%$ of breast cancer families with four or more cases of early onset breast cancer under the age of 60 show no convincing evidence of linkage to BRCA1 or $B R C A 2$ [9]. Nonetheless, for women without mutations in $B R C A 1$ or $B R C A 2$, family history remains a strong predictive risk factor for breast cancer [10-12]. This unexplained familial aggregation of the disease suggests the presence of additional high-risk, breast cancer susceptibility genes, particularly in non-BRCA1/2 families with many cases of early onset breast cancer [13].

The largest genome-wide breast cancer linkage study since the identification of BRCA2, conducted on 149 non-BRCA1/2 breast cancer families by the Breast Cancer Linkage Consortium, failed to find any significant linkage signals [14]. However, the selection criteria of the families, differences in the population background, or clinical and genetic heterogeneity might determine the power to detect a linkage signal. Rosa- Rosa et al performed linkage analysis in 41 breast-cancer Spanish families and found a significant linkage signal (HLOD score 3.55$)$ at 21q22. They also found a HLOD of 3.13 on the 3q25 region [15] in a subset of 13 families with bilateral breast cancer. Collectively, the published linkage studies [15-17] do not provide conclusive evidence that high risk $B R C A$-like genes exist, but certainly indicate that if they do, their mutations would only account for a small fraction of the non-BRCA1/2 families. Candidate gene approaches for mutation screening rely on $a$ priori information about biological gene function and are thus limited by how much is known about the biology of the disease. Identification of rare mutations in highly penetrant breast cancer susceptibility genes will therefore require the application of more novel strategies beyond that of traditional linkage and candidate gene approaches. A strategy for disease gene identification by NMD inhibition (GINI) utilising gene expression profiling has been developed to identify dysregulated transcripts which may carry protein truncating mutations, thereby allowing this approach to be used to prioritise genes for mutation analysis [18].

The Breast Cancer Information Core database (BIC; http://research.nhgri.nih.gov/bic/; version modified September 2010) states that almost $50 \%$ of all reported $B R C A 1$ mutations and about $30 \%$ of reported $B R C A 2$ mutations are either frameshift or nonsense mutations, thus it is reasonable to expect that protein truncating mutations will be common in any other highly penetrant breast cancer susceptibility genes. The NMD pathway selectively and rapidly degrades mutant messenger RNAs harbouring premature termination codons (PTCs) [19-21]. Therefore, blocking the NMD pathway will stabilise these mutant transcripts, which can then lead to the identification of potential tumour suppressor genes that contain nonsense mutations $[18,22]$. Such genome-wide screens for transcripts harbouring truncating mutations has proved successful in identifying sporadic nonsense mutations involved in colon cancer $[18,19,23,24]$, prostate cancer $[25,26]$, melanoma [27], mantle cell lymphoma [28] and clear cell renal cell carcinoma [29]. However, the approach has not yet been applied to identify germline mutations involved in breast cancer. In an attempt to identify additional high-risk genes involved in familial breast cancer, we have applied this disease-gene identification technique to affected and unaffected members of multiple- case non-BRCA1/2 breast cancer families.

\section{Methods}

\section{Selection of non-BRCA1/2 breast cancer families}

The Kathleen Cuningham Foundation Consortium for Research into Familial Breast Cancer (kConFab; http:// www.kconfab.org) provides a comprehensive resource upon which researchers can draw data and biospecimens for peer-reviewed, ethically- approved funded research projects on familial aspects of breast cancer. We selected three families (Family A, B and C) for use in GINI (Table 1), in which no BRCA1 or BRCA2 mutations had been found, and which had Manchester scores $>19$ $[30,31]$ suggesting a high probability of having a mutation in a breast cancer susceptibility gene. For each family, there were at least three LCLs from women affected with breast cancer at ages 34-56, and at least three from

Table 1 Multiple-case non-BRCA1/2 breast cancer families chosen for GINI analysis

\begin{tabular}{cccccccc}
\hline Family & $\begin{array}{l}\text { Manchester Score } \\
\text { BRCA1BRCA2 }\end{array}$ & $\begin{array}{l}\text { Number of LCLs } \\
\text { from individuals } \\
\text { affected with breast } \\
\text { cancer }\end{array}$ & $\begin{array}{l}\text { Ages of affected } \\
\text { individuals at the } \\
\text { time of their } \\
\text { diagnosis }\end{array}$ & $\begin{array}{l}\text { Number of LCLs } \\
\text { from individuals } \\
\text { unaffected by breast } \\
\text { cancer }\end{array}$ & $\begin{array}{l}\text { Ages of individuals } \\
\text { unaffected by breast } \\
\text { cancer }\end{array}$ & $\begin{array}{l}\text { Total number of } \\
\text { samples hybridised to } \\
\text { gene expression array }\end{array}$ \\
\hline A & 20 & 19 & 5 & $26,34,43,47,64$ & 3 & $32,38,63$ & 48 \\
B & 24 & 21 & 3 & $39,39,41$ & 4 & $26,28,57,58$ & 42 \\
C & 19 & 19 & 3 & $36,44,56$ & 6 & $41,45,62,68,70,72$ & 54 \\
\hline
\end{tabular}


women who were unaffected at ages 26-72. Ethical approvals were obtained from the Human Research Ethics Committees of the Queensland Institute of Medical Research and the Peter MacCallum Cancer Centre. Written informed consent was obtained from each participant.

\section{Cell lines}

We used the colon cancer cell line, HT29, which contains a truncating mutation (c.931C $>\mathrm{T}$ p.Q311X) in one allele of the SMAD4 gene and a deletion of the other allele, as a positive control, as well as two positive control LCLs (BRCA1 c.2681_2682delAA and BRCA2 c.539_541insAT). These truncating mutations occur $>55$ nucleotides upstream from the final exon of each gene and are thus expected to undergo nonsense-mediated mRNA decay. To identify putative novel, breast cancer susceptibility genes by GINI, we used 24 LCLs established from patients affected with breast cancer and unaffected individuals from three non-BRCA1/2 breast cancer families.

\section{Gene inhibition of nonsense mediated decay (GINI)}

Twenty-four hours prior to caffeine treatment, we seeded HT29 cells into two $75 \mathrm{~cm}^{2}$ cell culture flasks, each containing $1 \times 10^{6}$ cells in $10 \mathrm{mls}$ of tissue culture medium (RPMI-1640 + 10\% FBS). We then added fresh medium containing $10 \mathrm{mM}$ caffeine (Sigma-Aldrich, St. Louis, MO, USA) to one flask and fresh medium without caffeine to the control flask. After four hours of incubation at $37^{\circ} \mathrm{C}$, we removed the medium from both flasks and washed the cells twice with phosphate-buffered saline (PBS). We then added normal medium to the untreated control flask and treated the other flask for a further four hours with $10 \mathrm{mM}$ caffeine medium. We then removed the media from both flasks and washed the cells twice with PBS before storing the cells at $-80^{\circ} \mathrm{C}$ until RNA extraction. We repeated this process ten times to ensure repeatability of results. We then performed semi-quantitative real-time reverse transcriptase (RTPCR) of SMAD4 to confirm stabilisation of the target gene after caffeine treatment, and cRNA from four randomly selected replicates were then hybridised to the Illumina HumanHT-12 v3 gene expression arrays.

In order to determine the optimal caffeine concentration for treating LCLs, we treated $3.5 \times 10^{6}$ LCLs with $2.5 \mathrm{mM}, 5 \mathrm{mM}, 7.5 \mathrm{mM}, 10 \mathrm{mM}$ or $15 \mathrm{mM}$ caffeine (SigmaAldrich) for two lots of four-hour incubations at $37^{\circ} \mathrm{C}$ in the same GINI process described above for HT29 cells. We determined the optimal concentration by semiquantitative real-time RT-PCR of BRCA1 and BRCA2 (Additional File 1) and then performed three technical replicates of GINI on the positive control LCLs on different days, and hybridised the cRNA to Illumina HumanHT-12 v3 gene expression arrays.

\section{GINI on LCLs from non-BRCA1/2 breast cancer families}

Having optimised the GINI method on positive control LCLs with $B R C A 1$ or BRCA2 mutations, we applied it to LCLs from 11 affected and 13 unaffected individuals from three non-BRCA1/2 breast cancer families, in parallel with positive control HT29 cells. We performed three technical replicates for each sample on different days and then hybridised cRNA from caffeine-treated and untreated control samples to Illumina HumanHT12 v3 gene expression arrays.

\section{Semi-quantitative real-time reverse transcriptase PCR (RT-PCR) and expression array profiling}

We extracted total RNA from frozen cell pellets using the RNeasy RNA Extraction Kit (Qiagen, Hilden, Germany) as per the manufacturer's instructions. We used semiquantitative real-time reverse transcriptase PCR (RTPCR) to validate the expression of the target genes in the positive controls and of the candidate genes found by the GINI method. Primer sequences are provided in Additional File 2. We synthesised cDNA from $1 \mu \mathrm{g}$ of total RNA in a reaction volume of $20 \mu \mathrm{l}$ using oligodT and Superscript III (Invitrogen) according to manufacturer's instructions. The cDNA reactions were then diluted to $200 \mu \mathrm{l}(1: 10)$ in RNase/DNasefree water. We performed semi-quantitative real-time RT-PCR amplifications in quadruplet on the LightCycler480 (Roche) machine using $3.75 \mu$ l SYBR Green PCR Master Mix (Invitrogen) and $0.33 \mu \mathrm{M}$ forward and reverse primers in a total reaction volume of $7.5 \mu \mathrm{l}$, using the glyceraldehydes-3-phosphate dehydrogenase $(G A P D H)$ gene as a reference. We normalised the comparative threshold-cycle $(\mathrm{Ct})$ of signal intensities of amplified product to that of $G A P D H$ calibrating to the matched untreated control of each sample using the LightCycler480 software program (Roche Diagnostics Corp., Indianapolis, IN, USA).

For the expression profiling, we prepared biotinylated cRNA from 450ng of total RNA using the IlluminaTotalPrep RNA Amplification Kit (Ambion, Austin, TX, USA) and hybridised 750ng cRNA per sample to HumanHT-12 v3 Expression BeadChips (Illumina Inc., San Diego, CA, USA) as per the Whole-Genome Gene Expression Direct Hybridisation Assay protocol. We collated expression data using BeadStudio Version 1.5.1.3 (Illumina Inc.) and then quantile normalised the raw data using the $\mathrm{R}$ Bioconductor LUMI package [32]. Microarray data were submitted to Gene Expression Omnibus (GEO) [33] and are accessible through GEO (http://www. ncbi.nlm.nih.gov/geo/query/acc.cgi?acc=GSE37210). To identify differentially expressed genes, between each caffeine treated sample to its own untreated control over three technical replicates, we implemented a 
linear model and empirical Bayes method using the RBioconductor LIMMA package [34]. We considered genes with Benjamini and Hochberg adjusted P-values less than $5 \%$ that also have a greater than $50 \%$ chance of being differentially expressed (positive B- statistic) as having statistically significant changes in their expression profiles. We imported differentially expressed genes into GeneSpring v10.0 (Agilent Technologies) for visualisation and further analysis.

We defined genes that were differentially expressed between all untreated and all caffeine treated samples as "global caffeine response" genes. These genes are unlikely to contain truncating mutations in breast cancer susceptibility genes but are more likely to be expressed in response to caffeine or be naturally occurring NMD targets.

For each family, we selected candidate genes for semiquantitative real-time RT-PCR validation and mutations screening that were upregulated after caffeine treatment in the individuals affected with breast cancer but were not differentially expressed after caffeine treatment in their unaffected family members, and therefore not part of the "global caffeine response" gene list.

\section{Sequence analysis}

We sequenced the exonic and flanking splice sites of the one candidate gene we identified by GINI in the relevant family. We amplified 500ng DNA by polymerase chain reaction (PCR) with $1 \mathrm{X}$ PCR Buffer, $2.5 \mathrm{mM} \mathrm{MgCl}_{2}$, $0.2 \mathrm{mM}$ dNTP, $0.25 \mu \mathrm{M}$ forward and reverse primer, $0.4 \mu \mathrm{l}$ AmpliTaq Gold in a total reaction volume of $50 \mu \mathrm{l}$. We then purified the PCR products using the QIAquick PCR Purification Kit Spin Protocol (Qiagen) prior to sequencing according to manufacturer's instructions using BigDye Terminator v3.1 and an ABI 3100 Genetic Analyser (PE Applied Biosystems, Foster City, CA, USA).

\section{Haplotyping around the PPARGC1A region}

We used a total of six short tandem repeat microsatellite markers from a $2 \mathrm{Mb}$ region around PPARGC1A to haplotype around the PPARGC1A gene in members of Family B. We selected four markers (D4S3017, D4S2953, D4S425, D4S23013) (deCODE Genetics; http://www.decode.com) and designed two (19xTA and 20xTG) more around short tandem repeats within the DNA sequence of PPARGC1A and labelled either the forward or reverse primer with a 6-FAM label. We amplified 500ng DNA by polymerase chain reaction (PCR) with $1 \mathrm{X}$ PCR Buffer, 2.5mM $\mathrm{MgCl}_{2}, 0.2 \mathrm{mM} \mathrm{dNTP}, 0.25 \mu \mathrm{M}$ forward and reverse primer, $0.4 \mu \mathrm{l}$ AmpliTaq Gold in a $50 \mu \mathrm{l}$ final volume. Amplified PCR products were diluted 1:800 with $\mathrm{Hi}$-Di formamide/500 LIZ size standard mix (formamide to size standard ratio of 67:1) (Applied Biosystems) and the mixture was then denatured for $5 \mathrm{~min}$ at $95^{\circ} \mathrm{C}$. The samples were separated in an ABI PRISM3700 DNA Sequencer and subjected to the fragment analysis protocol. Allele scoring was performed using the GeneMapper 4.0 software (Applied Biosystems).

\section{Results}

\section{Optimisation of GINI}

We used HT29 cells to test the robustness of the GINI technique with caffeine treatment. Results from semiquantitative real-time RT-PCR validation of ten replicate experiments identified a consistent 2.5- to 3.7-fold upregulation of SMAD4 mRNA after $10 \mathrm{mM}$ caffeine treatment (Figure 1). Microarray results of three replicates identified a total of 553 probes corresponding to 495 genes that were significantly differentially expressed $\geq 2$ fold between untreated and caffeine-treated HT29 cells. When sorted by adjusted P-value, SMAD4 ranked as the $48^{\text {th }}$ most differentially expressed gene and the $28^{\text {th }}$ most

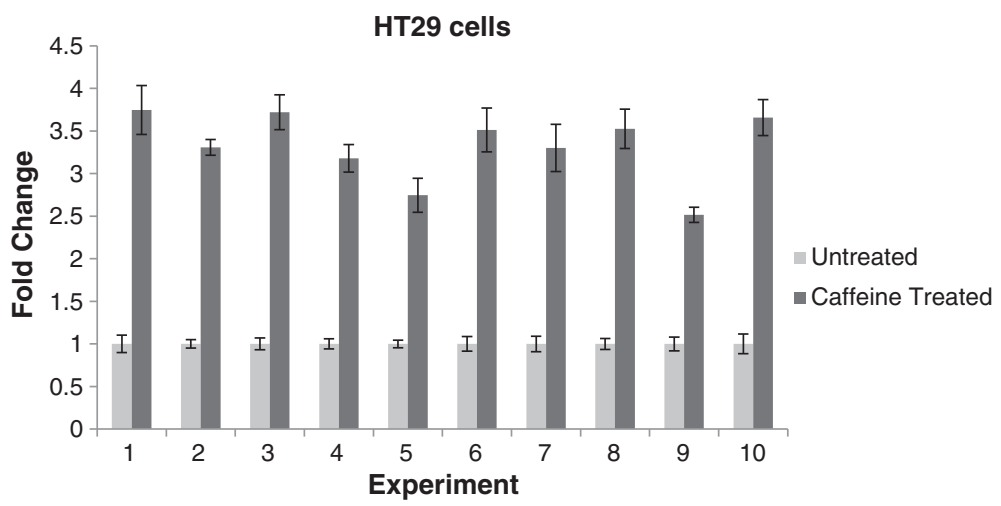

Figure 1 Stabilisation of SMAD4 mRNA in HT29 cells after caffeine (10mM) treatment measured by qRT-PCR. Each caffeine treated sample has been normalised to the housekeeping gene, GAPDH, and calibrated to its untreated equivalent. Error bars represent standard error of the mean of four technical replicates of each $P C R$ reaction. 
significantly upregulated gene (fold change $=2.78$; adj Pvalue $=7.83$-E07; $B$-statistic $=12.94$ ).

In parallel with positive control HT29 cells, we treated LCLs with known BRCA1 or BRCA2 mutations with a caffeine concentration gradient and used semiquantitative real-time RT-PCR to find the concentration that best stabilises their respective target genes (Additional File 1). The highest level of target gene stabilisation in the LCLs was 2.4 -fold at $7.5 \mathrm{mM}$ caffeine. We repeated the GINI experiments a total of three times for the BRCA1 and BRCA2 cell lines, and each replicate of every cell line showed at least a 1.5 -fold stabilisation of their respective target genes after treatment with $7.5 \mathrm{mM}$ caffeine (Figure 2).

\section{Identifying candidate breast cancer susceptibility genes} by $\mathrm{GINI}$ in nonBRCA1/2 breast cancer families

We applied GINI, with a caffeine concentration of $7.5 \mathrm{mM}$, to 24 LCLs from three non-BRCA1/2 families. We identified a set of 6,520 global caffeine response" genes which were differentially expressed (adjusted P-value $<0.0006$ and B-statistic $>0$ ) between untreated and caffeine treated samples from all individuals combined from the three families. Of these "global caffeine response" genes, 1,364 and 292 genes changed more than 1.5- and 2-fold after caffeine treatment, respectively.

We identified candidate protein truncated transcripts within each family as those with statistically significant increased expression after caffeine treatment in affected individuals of that family, but not in unaffected individuals of the other two families, and which were not part of the "global caffeine response" (Figure 3). We identified a total of two, two and five candidate genes for Family A, $\mathrm{B}$ and $\mathrm{C}$, respectively (Table 2). Interestingly, only one gene, peroxisome proliferator-activated receptor- $\gamma$ coactivator-1 $\alpha$ (PPARGC1A), was identified as a candidate in more than one family.

\section{Semi-quantitative real-time RT-PCR and sequencing of candidate breast cancer susceptibility genes}

We tried to validate all nine candidate genes in with semi-quantitative real-time RT-PCR but only PPARGC1A showed consistent stabilisation of mRNA transcript across replicates of Family B in individuals affected by breast cancer and not in their healthy family members (Figure 4 and Additional File 3-9, Additional File 4, Additional File 5, Additional File 6, Additional File 7, Additional File 8). Primer sequences are provided in Supplementary Table 1. The youngest individual in Family $B$ (individual 4: aged 26) showed statistically significant stabilisation of the PPARGC1A transcript in two out of three experimental replicates, suggesting that this individual may be a carrier for a family-specific breast cancer mutation but has not yet developed disease. However, sequencing of all coding regions in all affected and unaffected family members and flanking splice sites did not reveal any protein truncating mutations in PPARGC1A. We identified three coding (rs2970847, rs3755863 and rs8192678) and one non-coding (rs2946385) single nucleotide polymorphisms (SNPs). The only variant identified that was not listed in dbSNP as a common polymorphism was IVS7delT (Figure 5). However, this variant was found in all members sequenced including affected and unaffected individuals. Furthermore, Human Splicing Finder [35] suggested that this intronic variant has no effect on splicing. Haplotype analysis using short tandem repeat microsatellite markers spanning $2 \mathrm{Mb}$ around PPARGC1A showed no evidence of a haplotype that might carry a protein truncating mutations segregating with disease within the family (Figure 5).

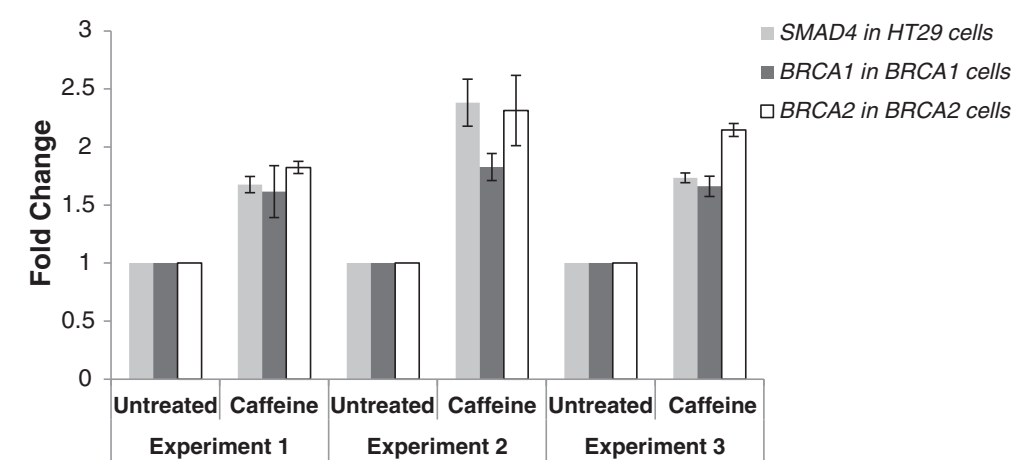

Figure 2 Stabilisation of target genes in HT29, BRCA1 and BRCA2 positive control cell lines after GINI with caffeine (7.5mM) treatment. Three experimental replicates of the GINI method were performed on HT29 cells, BRCA1 c.2681_2682delAA and BRCA2 c.539_541insAcontrol LCLs. GRT-PCR results indicate that each experimental replicate shows at least a 1.5-fold stabilisation of all three target genes after treatment with $7.5 \mathrm{mM}$ caffeine. Each sample has been normalised to the housekeeping gene, GAPDH, and calibrated to its untreated equivalent. Error bars represent standard error of the mean of four technical replicates of each PCR reaction. 


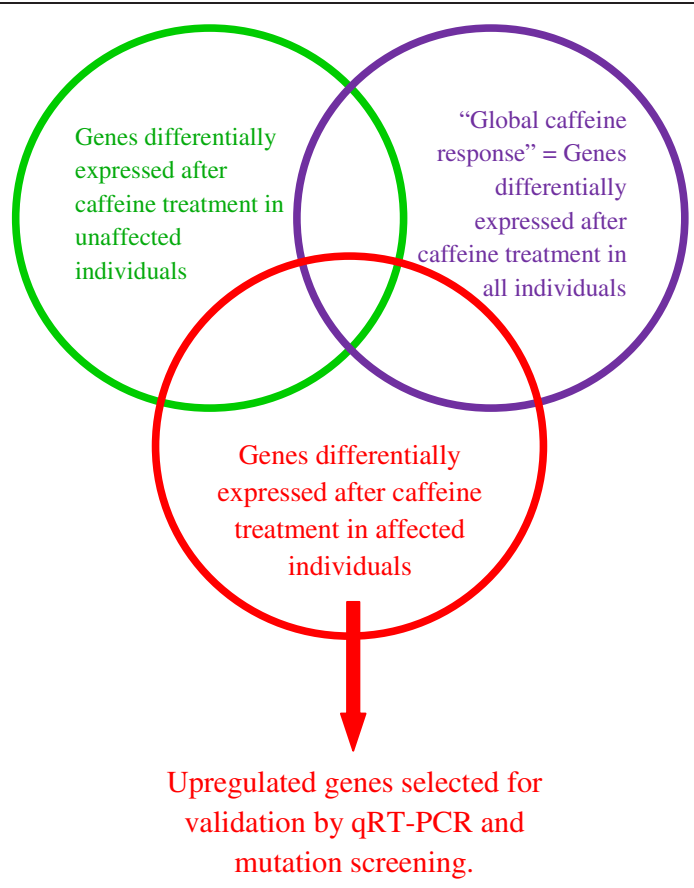

Family A

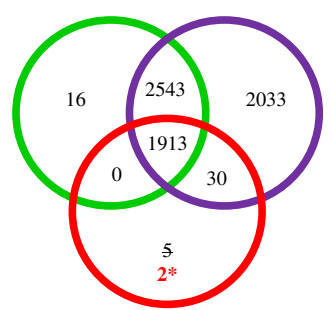

Family B

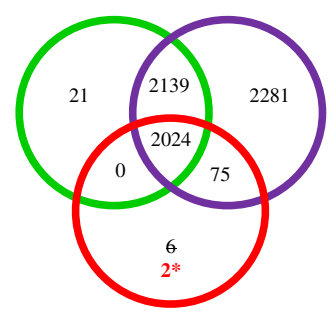

Family C

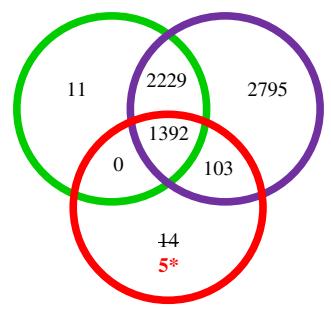

Figure 3 Identification of candidate breast cancer susceptibility genes for mutation screening in multiple-case non-BRCA1/2 breast cancer families. For each family, candidate genes included those that were upregulated after caffeine treatment in individuals affected with breast cancer but not in their unaffected family members and also not part of the "global caffeine response" gene list.

\section{Discussion}

In an attempt to identify germline mutations in additional high risk breast cancer susceptibility genes, we have optimised and applied the GINI method on lymphoblastoid cell lines derived from the blood of women from multiple-case non- BRCA1/2 breast cancer families. By using positive control cell lines with known truncating mutations, we have determined the optimal concentration of caffeine that results in significant stabilisation of target genes, which is suggestive of successful inhibition of the nonsense-mediated mRNA decay pathway. Microarray analysis of the transcripts stabilised after NMD inhibition by caffeine treatment in women affected with breast cancer compared to their unaffected relatives identified a total of eight different genes across three families. One gene, peroxisome proliferator- activated receptor- $\gamma$ coactivator-1 $\alpha$ (PPARGC1A), was a candidate gene in two families and was the only breast cancer susceptibility candidate gene that we could demonstrate by semi-quantitative real-time RT-PCR as being consistently upregulated after GINI in affected members of the family, but not in most unaffected relatives.

Table 2 Candidate genes identified by GINI analysis

\begin{tabular}{lcccc}
\hline Family & Gene Name & Fold Change & Adjusted P-value & B-statistic \\
\hline A & WNT5A & 1.14 & 0.005560 & 0.04 \\
& RAB3B & 1.17 & 0.004254 & 0.33 \\
B & PPARGC1A & 1.19 & $\mathbf{0 . 0 0 1 2 2 6}$ & 4.23 \\
& CD14 & 1.19 & 0.001875 & 1.19 \\
C & PPARGC1A & 1.41 & $\mathbf{3 . 0 0 E - 1 1}$ & 25.02 \\
& METRNL & 1.44 & 0.001146 & 2.51 \\
& BMP6 & 1.43 & $3.61 \mathrm{E}-05$ & 6.67 \\
& PRDM1 & 1.25 & 0.000314 & 4.04 \\
& GRSF1 & 1.69 & 0.007637 & 0.23 \\
\hline
\end{tabular}



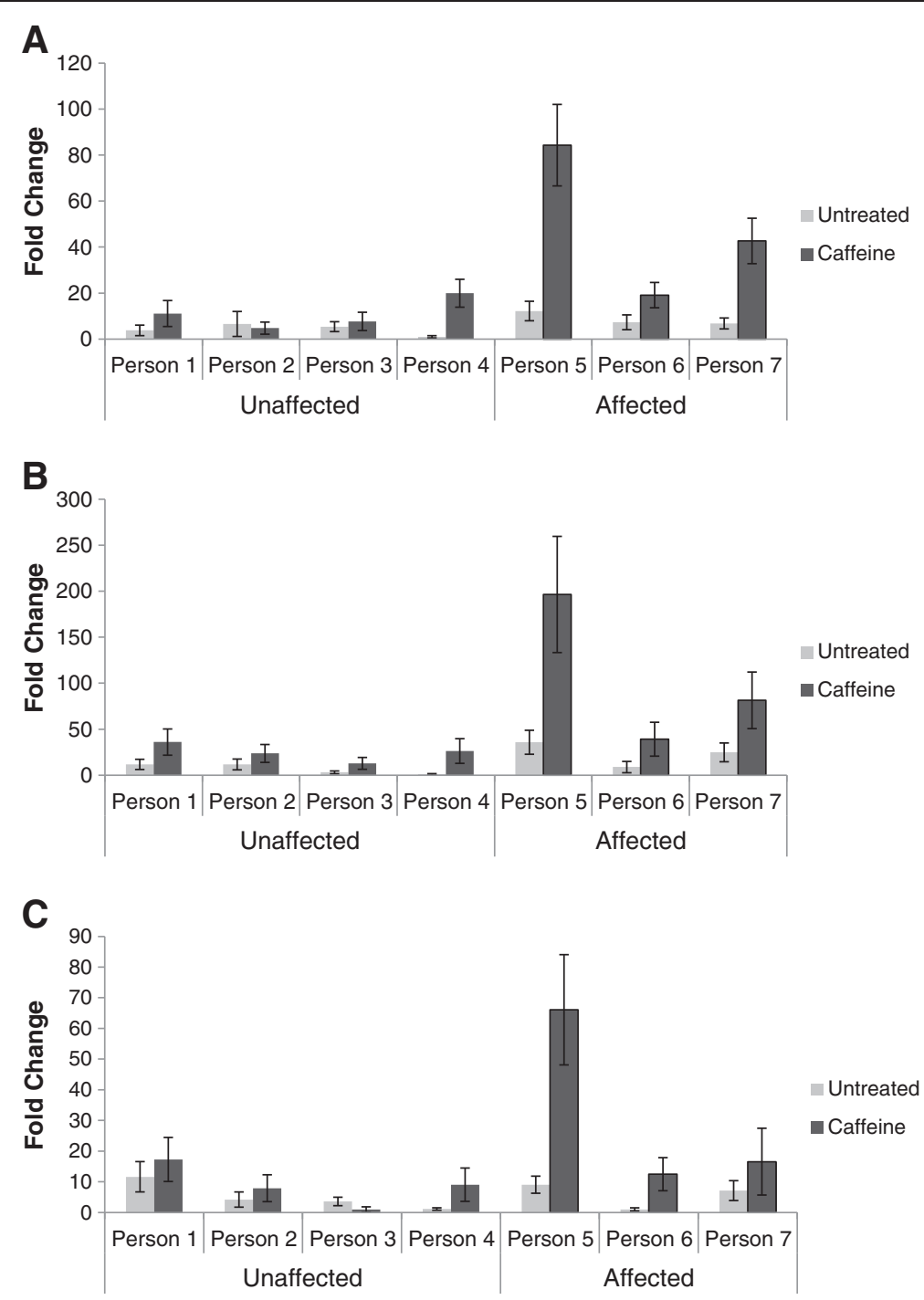

Figure 4 Stabilisation of PPARGC1A mRNA in the lymphoblastoid cell lines (LCLs) of individuals from Family B after caffeine (7.5mM) treatment measured by semi-quantitative real-time RT-PCR. PPARGC1A mRNA is stabilised in family members affected by breast cancer and not in unaffected family members, with the exception of Person 4. Each sample has been normalised to the housekeeping gene, GAPDH, and calibrated to the lowest expressing untreated sample. Standard error bars represent standard error from the mean of four technical replicates for each PCR reaction.

PPARGC1A is a master transcriptional regulator of mitochondrial oxidative phosphorylation and cellular energy metabolism. The gene is expressed in a broad range of tissues with higher levels of expression detected in tissues with high oxidative capacity, such as heart, skeletal muscle, brown adipocyte, kidney and brain [36-38]. Upregulation of PPARGC1A in response to oxidative stress can suppress the production of reactive oxygen species [39]. PPARGC1A also plays an important role as an estrogen receptor coactivator in the estrogen receptor (ER) pathway by binding and enhancing transactivation of estrogen receptor alpha $(E R \alpha)$ in a ligand-dependent manner [40,41]. Persistent estrogen mediated mitogen signalling of ER $\alpha$ has been known to stimulate the growth of a large proportion of breast cancers [42-45]. In fact, over half of all breast cancers overexpress ER $\alpha$ [46]. An association study of $~ 800$ BRCA1/2 mutationnegative familial breast cancer cases and over 1,000 controls from Germany found some evidence that the PPARGC1A Thr612Met polymorphism might be a risk factor for familial breast cancer $(\mathrm{OR}=1.35,95 \%$ CI 1.00 1.81, $P=0.049)$, high-risk familial breast cancer $(\mathrm{OR}=$ 1.51, 95\% CI 1.08-2.12, $P=0.017)$ and bilateral familial breast cancer $(\mathrm{OR}=2.30,95 \%$ CI 1.24-4.28, $P=0.009$ ) [47]. However, haplotype analysis did not identify any additional association with familial breast cancer [47].

Although, we did not identify any truncating mutations in the coding or splice site regions of PPARGC1A, 


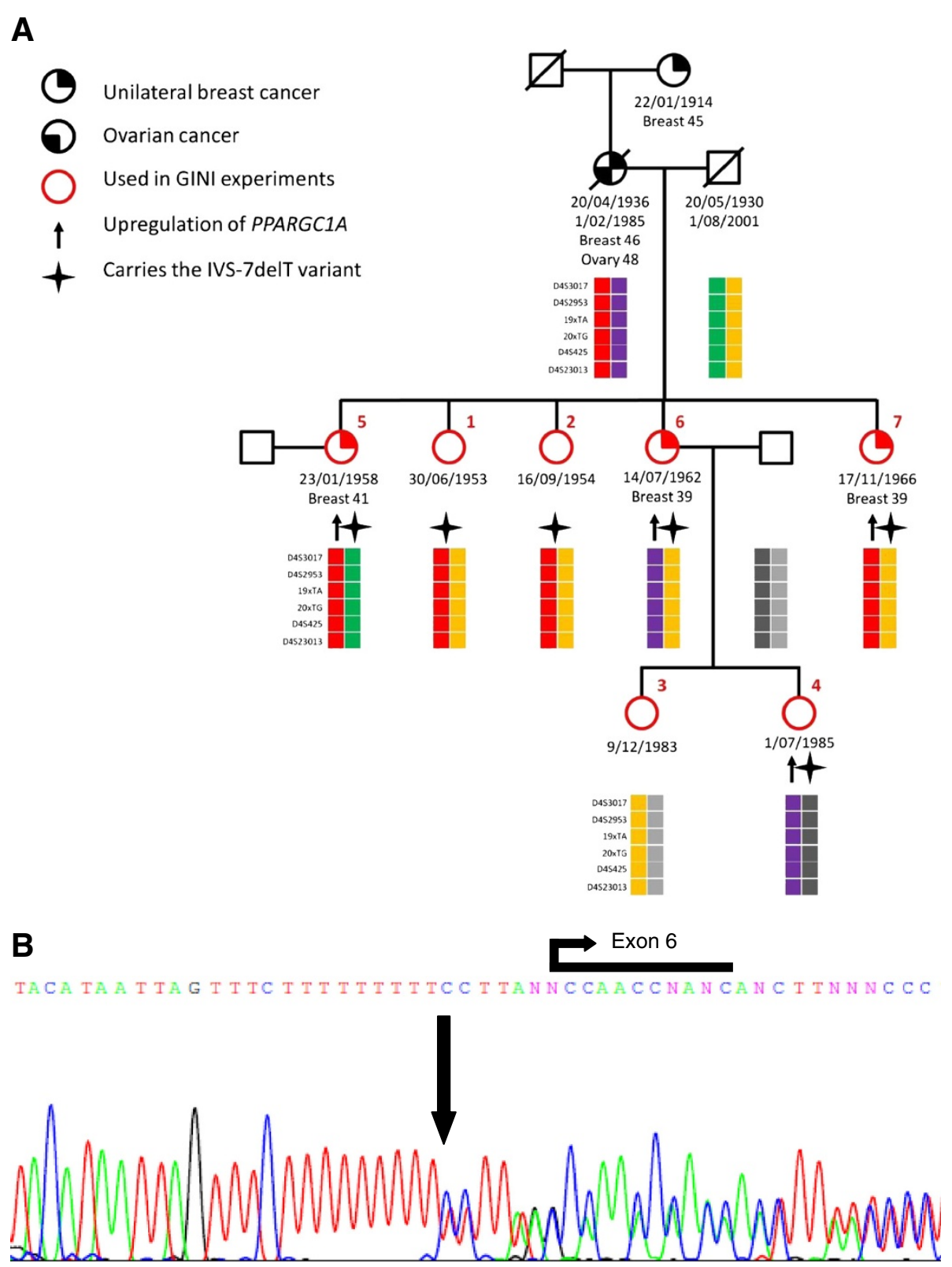

Figure 5 Pedigree of Family B (A) and sequencing chromatogram of PPARGC1A IVS-7delT variant (B). GINI experiments were performed on the $L C L s$ derived from individuals marked with red circles. The red coloured numbers correspond to the person number in Figure 4 . Upward arrows indicate individuals that showed stabilisation of the PPARGC1A transcript. The IVS-7delT variant (B) is located seven base pairs upstream from the start of exon 6 and was found in both affected and unaffected members of Family B as indicated by stars in the pedigree.

we did find an IVS-7delT variant in both affected and unaffected individuals of two families. However, haplotyping analysis around PPARGC1A did not identify a haplotype that segregated with disease in either family, which may contain a cryptic, deeply intronic, mutation that causes protein truncation.

Caffeine can impact on the alternative splicing of a subset of cancer-associated genes [48]. For example, caffeine can result in alternatively spliced isoforms of chaperonin- containing TCP1 subunit 3 (CCT3), asparagine synthetise (ASNS), COMM-domain containing 5 (COMMD5), ATP binding cassette subfamily F member 2 (ABCF2), SLC39A1/ZIRTL, and yippee-like 5 gene (YPEL5) being expressed. Exposure of HeLa cells to caffeine can also result in differential expression of 40 cancer-associated gene (for example, KLF6, SC35, CCT3, ASNS, COMMD5, $A B C F 2, Y P E L 5)$ isoforms [48], although it is worth noting that different patterns of gene expression result from differing concentrations of caffeine [49]. Nevertheless, even though increased stability of mutant RNA is suggested to 
be more likely [18], GINI does not distinguish between the increased stability of the mutant transcript and the selective depletion of the normal transcript [50]. Therefore, if NMD inhibition by caffeine treatment did result in the stabilisation of one transcript and the reduction of another isoform, then unless the probes present on the microarray can distinguish between these isoforms, the net change in gene expression may not have been detected on the array platform. Furthermore, nonsense codons can reduce the abundance of nuclear mRNA without affecting the abundance of premRNA or the half-life of cytoplasmic mRNA [51] and this might further reduce the sensitivity of GINI.

In order to acquire a more selective list of nonsense transcripts for a particular cell line, it may be necessary to combine the results of multiple different methods of NMD inhibition: 1) siRNA against UPF1 [52,53], 2) caffeine treatment, and 3) emetine treatment, which inhibits the progression of the ribosome along the mRNA $[29,54]$. A major problem with using the GINI approach for identifying pathogenic mutations in yet-unidentified high-risk breast cancer genes in the germline DNA of individuals affected with breast cancer is that the mutation is expected to be present in a heterozygous state (at least, in an autosomal dominant disorder). The stabilisation of only one allele reaches the sensitivity limits of gene expression microarrays. Therefore, genes that may have been mutated but are expressed at a moderate to low level may have been excluded from detection. Tumour suppressor genes are usually inactivated during the process of tumorigenesis by a two-step process involving an inactivating mutation in the target gene accompanied by loss of the wildtype allele. However, in LCLs established from peripheral blood mononuclear leukocytes, the normal wildtype allele could mask the effects of GINI on the mutated allele thus reducing the efficiency of GINI [55]. Furthermore, LCLs may not provide an accurate representation of genes that are active in breast tissue, and if the putative breast cancer susceptibility gene is not expressed in LCLs then GINI will not work to identify susceptibility genes.

There is also evidence to suggest that NMD efficiency varies between different people with the same mutation [56,57], between different tissue types within an organism $[58,59]$, and even between different strains of the same cell type [60]. It is possible that variable efficiencies of NMD can influence the clinical outcome of hereditary and acquired genetic disease and thus act as a genetic modifier of human genetic diseases.

Inhibition of the nonsense-mediated mRNA decay pathway followed by microarray analysis has been successfully applied to cancer cell lines to identify protein truncating mutations that may underlie sporadic forms of cancer $[19,23,25-29,54]$. The GINI method has recently been applied to the LCLs from six prostate cancer patients and their healthy brothers in order to identify susceptibility genes in hereditary prostate cancer [55]. However, despite sequencing 17 candidate genes, no truncating mutations were found. The GINI method has also failed to identify putative tumour suppressor genes in gastric cancer cell lines with siRNA against UPF1 [61]. It is commonly reported that the GINI strategy leads to a high number of false positives $[19,21,23,26-28,55,61,62]$. The novelty of our approach is the ability to identify transcripts stabilised by NMD inhibition in multiple breast cancer patients within a family and compare this gene list to the transcripts that are stabilised in multiple unaffected members of the same family in an attempt to reduce the number of false positive hits. Despite this analysis identifying few candidate genes per family, we did not identify any detectable nonsense mutations. Therefore, our GINI analysis also results in a high number of false positives. However, it is also possible that the mechanism underlying susceptibility to breast cancer in non$B R C A 1 / 2$ families may not be due to truncating mutations in susceptibility genes.

\section{Conclusion}

In summary, we applied the gene identification by nonsense-mediated mRNA decay inhibition (GINI) strategy to lymphoblastoid cell lines established from the blood of affected and unaffected members of three multiple-case non-BRCA1/2 breast cancer families but we did not identify any nonsense mutations that may underlie the breast cancer risk in any of the three families investigated. The application of the GINI method to identify germline mutations is challenging due to limitations including microarray sensitivity in detecting small fold changes, and because of individual variations in nonsense-mediated mRNA decay efficiency $[24,50,56,59,60,63]$.

With the plummeting costs of next generation sequencing technologies, sequencing of whole exomes and genomes is becoming a much more attractive method to identify rare, yet high risk, pathogenic mutations underlying human genetic disease.

\section{Additional files}

Additional file 1: Optimisation of caffeine concentration for lymphoblastoid cell lines (LCLs). Level of mRNA stabilisation for two biological replicates of SMAD4 in HT29 (A), BRCA1 in BRCA1 c.2681_2682delAA LCL (B), BRCA2 in BRCA2 c.6275_6276delTT LCL (C) and BRCA2 in BRCA2 C.539_541insAT LCL (D) after treatment with different 
concentrations of caffeine (untreated - $15 \mathrm{mM}$ ). Error bars represent standard error of the mean.

Additional file 2: Primer sequences used for semi-quantitative realtime reverse transcriptase PCR of candidate genes identified with the GINI technique.

\section{Additional file 3: Stabilisation of WNT5A mRNA in the} lymphoblastoid cell lines (LCLs) of individuals from Family A after caffeine $(7.5 \mathrm{mM})$ treatment measured by semi-quantitative realtime RT-PCR. Each sample has been normalised to the housekeeping gene, GAPDH, and calibrated to the lowest expressing untreated sample to show variation in transcript expression across individuals. Standard error bars represent standard error from the mean of four technical replicates for each PCR reaction.

\section{Additional file 4: Stabilisation of RAB3B mRNA in the} lymphoblastoid cell lines (LCLs) of individuals from Family A after caffeine $(7.5 \mathrm{mM})$ treatment measured by semi-quantitative realtime RT-PCR. Each sample has been normalised to the housekeeping gene, GAPDH, and calibrated to the lowest expressing untreated sample to show variation in transcript expression across individuals. Standard error bars represent standard error from the mean of four technical replicates for each $\mathrm{PCR}$ reaction.

Additional file 5: Stabilisation of CD14 mRNA in the lymphoblastoid cell lines (LCLs) of individuals from Family B after caffeine (7.5mM) treatment measured by semi-quantitative real-time RT-PCR. Each sample has been normalised to the housekeeping gene, GAPDH, and calibrated to the lowest expressing untreated sample to show variation in transcript expression across individuals. Standard error bars represent standard error from the mean of four technical replicates for each PCR reaction.

Additional file 6: Stabilisation of PPARGC1A mRNA in the lymphoblastoid cell lines (LCLs) of individuals from Family C after caffeine $(7.5 \mathrm{mM})$ treatment measured by semi-quantitative realtime RT-PCR. Each sample has been normalised to the housekeeping gene, GAPDH, and calibrated to the lowest expressing untreated sample to show variation in transcript expression across individuals. Standard error bars represent standard error from the mean of four technical replicates for each PCR reaction.

\section{Additional file 7: Stabilisation of METRNL mRNA in the} lymphoblastoid cell lines (LCLs) of individuals from Family C after caffeine $(7.5 \mathrm{mM})$ treatment measured by semi-quantitative realtime RT-PCR. Each sample has been normalised to the housekeeping gene, GAPDH, and calibrated to the lowest expressing untreated sample to show variation in transcript expression across individuals. Standard error bars represent standard error from the mean of four technical replicates for each PCR reaction.

Additional file 8: Stabilisation of BMP6 mRNA in the lymphoblastoid cell lines (LCLs) of individuals from Family $C$ after caffeine $(7.5 \mathrm{mM})$ treatment measured by semi-quantitative realtime RT-PCR. Each sample has been normalised to the housekeeping gene, GAPDH, and calibrated to the lowest expressing untreated sample to show variation in transcript expression across individuals. Standard error bars represent standard error from the mean of four technical replicates for each PCR reaction.

Additional file 9: Stabilisation of GRSF1 mRNA in the lymphoblastoid cell lines (LCLs) of individuals from Family $C$ after caffeine $(7.5 \mathrm{mM})$ treatment measured by semi-quantitative realtime RT-PCR. Each sample has been normalised to the housekeeping gene, GAPDH, and calibrated to the lowest expressing untreated sample to show variation in transcript expression across individuals. Standard error bars represent standard error from the mean of four technical replicates for each $P C R$ reaction.

\section{Abbreviations}

NMD: nonsense-mediated mRNA decay; GINI: gene identification by nonsense-mediated mRNA decay inhibition; LCL: lymphoblastoid cell line; PTC: premature termination codon; LOH: loss of heterozygosity; RNAi: RNA interference; siRNA: small interfering RNA; PCR: polymerase chain reaction; RT-PCR: reverse transcriptase PCR; FBS: fetal bovine serum; EBV: Epstein-Barr virus; PBS: phosphate-buffered saline; KConFab: the Kathleen Cuningham Foundation Consortium for Research into Familial Breast Cancer; Ct: cycle threshold.

\section{Competing interests}

The authors declare that they have no competing interests.

\section{Acknowledgements}

We wish to thank Heather Thorne, Eveline Niedermayr, all the kConFab research nurses and staff, the heads and staff of the Family Cancer Clinics, and the Clinical Follow Up Study (funded 2001-2009 by NHMRC and currently by the National Breast Cancer Foundation and Cancer Australia \#628333) for their contributions to this resource, and the many families who contribute to kConFab. kConFab is supported by grants from the National Breast Cancer Foundation, the National Health and Medical Research Council (NHMRC) and by the Queensland Cancer Fund, the Cancer Councils of New South Wales, Victoria, Tasmania and South Australia, and the Cancer Foundation of Western Australia. We would also like to thank Sue Healey for her assistance in sequencing candidate genes and Igor Makunin for his advice during manuscript preparation. JKJ was financially supported by a scholarship from The Cancer Council Queensland. GCT is an NHMRC Senior Principal Research Fellow.

\section{Author details}

${ }^{1}$ Queensland Institute of Medical Research, Brisbane, Australia. ${ }^{2}$ School of Medicine, University of Queensland, Brisbane, Australia. ${ }^{3}$ Queensland Centre for Medical Genomics, Institute for Molecular Bioscience, The University of Queensland, Brisbane, Australia. ${ }^{4}$ The Kathleen Cuningham Foundation for Research into Familial Breast Cancer (kConFab), Peter MacCallum Cancer Centre, Melbourne, Australia. ${ }^{5}$ Queensland Institute of Medical Research, Royal Brisbane Hospital, Locked bag 2000, Herston, Brisbane, QLD 4029, Australia.

\section{Authors' contributions}

JKJ carried out the experiments and drafted the manuscript. NW participated in the design of the study and advised on data analysis. kConFab provided all the sample material. GCT conceived of the study. All authors read and approved the final manuscript.

Received: 6 December 2011 Accepted: 15 June 2012 Published: 15 June 2012

\section{References}

1. Frischmeyer PA, Dietz HC: Nonsense-mediated mRNA decay in health and disease. Human Molecular Genetics 1999, 8:1893-1900.

2. Easton DF: How many more breast cancer predisposition genes are there?. Breast Cancer Research 1999, 1:14-17.

3. Ponder BA, Antoniou A, Dunning A, Easton DF, Pharoah PD: Polygenic inherited predisposition to breast cancer. Cold Spring Harb Symp Quant Biol 2005, 70:35-41.

4. Szabo Cl, King MC: Population genetics of BRCA1 and BRCA2. Am J Hum Genet 1997, 60:1013-1020

5. Antoniou A, Pharoah PD, Narod S, Risch HA, Eyfjord JE, Hopper JL, Loman N Olsson $\mathrm{H}$, Johannsson $\mathrm{O}$, Borg $\mathrm{A}$, et al: Average risks of breast and ovarian cancer associated with BRCA1 or BRCA2 mutations detected in case Series unselected for family history: a combined analysis of 22 studies. Am J Hum Genet 2003, 72:1117-1130.

6. Serova OM, Mazoyer S, Puget N, Dubois V, Tonin P, Shugart YY, Goldgar D, Narod SA, Lynch HT, Lenoir GM: Mutations in BRCA1 and BRCA2 in breast cancer families: are there more breast cancer-susceptibility genes?. Am J Hum Genet 1997, 60:486-495.

7. Schubert EL, Lee MK, Mefford HC, Argonza RH, Morrow JE, Hull J, Dann JL, King MC: BRCA2 in American families with four or more cases of breast or ovarian cancer: recurrent and novel mutations, variable expression, penetrance, and the possibility of families whose cancer is not attributable to BRCA1 or BRCA2. Am J Hum Genet 1997, 60:1031-1040.

8. Peto J, Collins N, Barfoot R, Seal S, Warren W, Rahman N, Easton DF, Evans C, Deacon J, Stratton MR: Prevalence of BRCA1 and BRCA2 gene mutations in patients with early-onset breast cancer. J Nat/ Cancer Inst 1999, 91:943-949. 
9. Ford D, Easton DF, Stratton M, Narod S, Goldgar D, Devilee P, Bishop DT, Weber B, Lenoir G, Chang-Claude J, et al: Genetic heterogeneity and penetrance analysis of the BRCA1 and BRCA2 genes in breast cancer families. The Breast Cancer Linkage Consortium. American Journal of Human Genetics 1998, 62:676-689.

10. Claus EB, Schildkraut J, Iversen ES Jr, Berry D, Parmigiani G: Effect of BRCA and BRCA2 on the association between breast cancer risk and family history. J Natl Cancer Inst 1998, 90:1824-1829.

11. Peto J, Mack TM: High constant incidence in twins and other relatives of women with breast cancer. Nat Genet 2000, 26:411-414

12. Lichtenstein P, Holm NV, Verkasalo PK, Iliadou A, Kaprio J, Koskenvuo M, Pukkala E, Skytthe A, Hemminki K: Environmental and heritable factors in the causation of cancer-analyses of cohorts of twins from Sweden, Denmark, and Finland. N Engl J Med 2000, 343:78-85.

13. Antoniou AC, Pharoah PD, McMullan G, Day NE, Stratton MR, Peto J, Ponder $B J$, Easton DF: A comprehensive model for familial breast cancer incorporating BRCA1, BRCA2 and other genes. Br J Cancer 2002, 86:76-83.

14. Smith P, McGuffog L, Easton DF, Mann GJ, Pupo GM, Newman B, ChenevixTrench G, Investigators kConFab, Szabo C, Southey M, et al: A genome wide linkage search for breast cancer susceptibility genes. Genes. Chromosomes and Cancer 2006, 45:646-655.

15. Rosa-Rosa JM, Pita G, Urioste M, Llort G, Brunet J, Lazaro C, Blanco I, Ramon y Cajal T, Diez O, de la Hoya M, et al: Genome-wide linkage scan reveals three putative breast-cancer-susceptibility loci. Am J Hum Genet 2009, 84:115-122.

16. Gonzalez-Neira A, Rosa-Rosa JM, Osorio A, Gonzalez E, Southey M, Sinilnikova O, Lynch H, Oldenburg RA, van Asperen CJ, Hoogerbrugge N, et al: Genomewide high-density SNP linkage analysis of non-BRCA1/2 breast cancer families identifies various candidate regions and has greater power than microsatellite studies. BMC Genomics 2007, 8:299.

17. Rosa-Rosa JM, Pita G, Gonzalez-Neira A, Milne RL, Fernandez V, Ruivenkamp C, van Asperen CJ, Devilee P, Benitez J: A 7 Mb region within 11 q13 may contain a high penetrance gene for breast cancer. Breast Cancer Res Treat 2009, 118:151-159.

18. Noensie EN, Dietz HC: A strategy for disease gene identification through nonsense-mediated mRNA decay inhibition. Nature Biotechnology 2001, 19:434-439.

19. Ionov Y, Nowak N, Perucho M, Markowitz S, Cowell JK: Manipulation of nonsense mediated decay identifies gene mutations in colon cancer Cells with microsatellite instability Oncogene 2004, 23:639-645.

20. Maquat LE: Nonsense-mediated mRNA decay in mammals. Journal of Cell Science 2005, 118:1773-1776.

21. Wolf M, Edgren H, Muggerud A, Kilpinen S, Huusko P, Sorlie T, Mousses S, Kallioniemi O: NMD microarray analysis for rapid genome-wide screen of mutated genes in cancer. Cell Oncology 2005, 27:169-173.

22. Khajavi M, Inoue K, Lupski JR: Nonsense-mediated mRNA decay modulates clinical outcome of genetic disease. European Journal of Human Genetics 2006, 14:1074-1081.

23. Ivanov I, Lo KC, Hawthorn L, Cowell JK, lonov Y: Identifying candidate colon cancer tumor suppressor genes using inhibition of nonsensemediated mRNA decay in colon cancer cells. Oncogene 2007, 26 2873-2884.

24. El-Bchiri J, Guilloux A, Dartigues P, Loire E, Mercier D, Buhard O, Sobhani I, de la Grange P, Auboeuf D, Praz F, et al: Nonsense-mediated mRNA decay impacts MSI-driven carcinogenesis and anti-tumor immunity in colorectal cancers. PLOS ONE 2008, 3:e2583.

25. Huusko P, Ponciano-Jackson D, Wolf M, Kiefer JA, Azorsa DO, Tuzmen S, Weaver D, Robbins C, Moses T, Allinen M, et al: Nonsense-mediated decay microarray analysis identifies mutations of EPHB2 in human prostate cancer. Nature Genetics 2004, 36:979-983.

26. Rossi MR, Hawthorn L, Platt J, Burkhardt T, Cowell JK, Ionov Y: Identification of inactivating mutations in the JAK1, SYNJ2, and CLPTM1 genes in prostate cancer cells using inhibition of nonsensemediated decay and microarray analysis. Cancer Genetics and Cytogenetics 2005, 161:97-103.

27. Bloethner S, Mould A, Stark M, Hayward NK: Identification of ARHGEF17, DENND2D, FGFR3, and RB1 mutations in melanoma by inhibition of nonsense-mediated mRNA decay. Genes Chromosomes Cancer 2008, 47:1076-1085

28. Pinyol M, Bea S, Pla L, Ribrag V, Bosq J, Rosenwald A, Campo E, Jares P: Inactivation of RB1 in mantle-cell lymphoma detected by nonsensemediated mRNA decay pathway inhibition and microarray analysis. Blood 2007, 109:5422-5429.

29. Duns G, van den Berg E, van Duivenbode I, Osinga J, Hollema H, Hofstra RM, Kok K: Histone methyltransferase gene SETD2 is a novel tumor suppressor gene in clear cell renal cell carcinoma. Cancer Res 2010, 70:4287-4291.

30. Evans DG, Eccles DM, Rahman N, Young K, Bulman M, Amir E, Shenton A, Howell A, Lalloo F: A new scoring system for the chances of identifying a BRCA1/2 mutation outperforms existing models including BRCAPRO. J Med Genet 2004, 41:474-480.

31. Evans DG, Lalloo F, Wallace A, Rahman N: Update on the Manchester Scoring System for BRCA1 and BRCA2 testing. J Med Genet 2005, 42:e39.

32. Du P, Kibbe WA, Lin SM: lumi: a pipeline for processing Illumina microarray. Bioinformatics 2008, 24:1547-1548.

33. Edgar R, Domrachev M, Lash AE: Gene Expression Omnibus: NCBI gene expression and hybridization array data repository. Nucleic Acids Res 2002, 30:207-210.

34. Smyth GK: Linear models and empirical bayes methods for assessing differential expression in microarray experiments. Stat Appl Genet Mol Biol 2004, 3:Article3.

35. Desmet FO, Hamroun D, Lalande M, Collod-Beroud G, Claustres M, Beroud C: Human Splicing Finder: an online bioinformatics tool to predict splicing signals. Nucleic Acids Res 2009, 37:e67

36. Esterbauer $\mathrm{H}$, Oberkofler $\mathrm{H}$, Krempler $\mathrm{F}$, Patsch $\mathrm{W}$ : Human peroxisome proliferator activated receptor gamma coactivator 1 (PPARGC1) gene: cDNA sequence, genomic organization, chromosomal localization, and tissue expression. Genomics 1999, 62:98-102.

37. Knutti D, Kaul A, Kralli A: A tissue-specific coactivator of steroid receptors, identified in a functional genetic screen. Mol Cell Biol 2000, 20:2411-2422.

38. Wu Z, Puigserver P, Andersson U, Zhang C, Adelmant G, Mootha V, Troy A, Cinti S, Lowell B, Scarpulla RC, Spiegelman BM: Mechanisms controlling mitochondrial biogenesis and respiration through the thermogenic coactivator PGC-1. Cell 1999, 98:115-124.

39. St-Pierre J, Lin J, Krauss S, Tarr PT, Yang R, Newgard CB, Spiegelman BM: Bioenergetic analysis of peroxisome proliferator-activated receptor gamma coactivators 1alpha and 1beta (PGC-1alpha and PGC-1beta) in muscle cells. J Bio/ Chem 2003, 278:26597-26603.

40. Kressler D, Schreiber SN, Knutti D, Kralli A: The PGC-1-related protein PERC is a selective coactivator of estrogen receptor alpha. J Biol Chem 2002, 277:13918-13925.

41. Tcherepanova I, Puigserver P, Norris JD, Spiegelman BM, McDonnell DP: Modulation of estrogen receptor-alpha transcriptional activity by the coactivator PGC-1. J Biol Chem 2000, 275:16302-16308.

42. Platet N, Cathiard AM, Gleizes M, Garcia M: Estrogens and their receptors in breast cancer progression: a dual role in cancer proliferation and invasion. Crit Rev Oncol Hematol 2004, 51:55-67.

43. Anderson E: The role of oestrogen and progesterone receptors in human mammary development and tumorigenesis. Breast Cancer Res 2002, 4:197-201

44. Roger P, Daures JP, Maudelonde T, Pignodel C, Gleizes M, Chapelle J, MartyDouble C, Baldet P, Mares P, Laffargue F, Rochefort H: Dissociated overexpression of cathepsin D and estrogen receptor alpha in preinvasive mammary tumors. Hum Pathol 2000, 31:593-600.

45. Osborne CK: Steroid hormone receptors in breast cancer management. Breast Cancer Res Treat 1998, 51:227-238.

46. Ali S, Coombes RC: Estrogen receptor alpha in human breast cancer: occurrence and significance. J Mammary Gland Biol Neoplasia 2000, 5: 271-281.

47. Wirtenberger M, Tchatchou S, Hemminki K, Schmutzhard J, Sutter C, Schmutzler RK, Meindl A, Wappenschmidt B, Kiechle M, Arnold N, et al: Associations of genetic variants in the estrogen receptor coactivators PPARGC1A, PPARGC1B and EP300 with familial breast cancer. Carcinogenesis 2006, 27:2201-2208.

48. Shi J, Hu Z, Pabon K, Scotto KW: Caffeine regulates alternative splicing in a subset of cancer-associated genes: a role for SC35. Mol Cell Biol 2008, 28:883-895

49. Yu L, Coelho JE, Zhang X, Fu Y, Tillman A, Karaoz U, Fredholm BB, Weng Z, Chen JF: Uncovering multiple molecular targets for caffeine using a drug target validation strategy combining A $2 \mathrm{~A}$ receptor knockout mice with microarray profiling. Physiol Genomics 2009, 37:199-210. 
50. Jeganathan D, Fox MF, Young JM, Yates JR, Osborne JP, Povey S: Nonsensemediated RNA decay in the TSC1 gene suggests a useful tool pre- and post-positional cloning. Hum Genet 2002, 111:555-565.

51. Cheng J, Maquat LE: Nonsense codons can reduce the abundance of nuclear mRNA without affecting the abundance of pre-mRNA or the halflife of cytoplasmic mRNA. Mol Cell Biol 1993, 13:1892-1902.

52. Mendell JT,Ap Rhys CMJ, Dietz HC: Separable roles for rent1/hUpf1 in altered splicing and decay of nonsense transcripts. Science 2002 , 298:419-422.

53. Mendell JT, Sharifi NA, Meyers $J$, Martinez-Murillo F, Dietz HC: Nonsense surveillance regulates expression of diverse classes of mammalian transcripts and mutes genomic noise. Nature Genetics 2004, 36:1073-1078.

54. Shin N, You KT, Lee H, Kim WK, Song M, Choi HJ, Rhee H, Nam SW, Kim H: Identification of frequently mutated genes with relevance to nonsense mediated mRNA decay in the high microsatellite instability cancers. Int J Cancer 2010,128:287-2880.

55. Mattila $H$, Schindler $M$, Isotalo J, Ikonen T, Vihinen M, Oja H, Tammela TL, Wahlfors T, Schleutker J: NMD and microRNA expression profiling of the HPCX1 locus reveal MAGEC1 as a candidate prostate cancer predisposition gene. BMC Cancer 2011, 11:327.

56. Linde L, Boelz S, Neu-Yilik G, Kulozik AE, Kerem B: The efficiency of nonsense-mediated mRNA decay is an inherent character and varies among different cells. Eur J Hum Genet 2007, 15:1156-1162.

57. Resta N, Susca FC, Di Giacomo MC, Stella A, Bukvic N, Bagnulo R, Simone C, Guanti G: A homozygous frameshift mutation in the ESCO2 gene: evidence of intertissue and interindividual variation in Nmd efficiency. J Cell Physiol 2006, 209:67-73.

58. Bahassi el M, Penner CG, Robbins SB, Tichy E, Feliciano E, Yin M, Liang L, Deng L, Tischfield JA, Stambrook PJ: The breast cancer susceptibility allele CHEK2*1100delC promotes genomic instability in a knock-in mouse model. Mutat Res 2007, 616:201-209.

59. Zetoune AB, Fontaniere S, Magnin D, Anczukow O, Buisson M, Zhang CX, Mazoyer S: Comparison of nonsense-mediated mRNA decay efficiency in various murine tissues. BMC Genet 2008, 9:83.

60. Viegas MH, Gehring NH, Breit S, Hentze MW, Kulozik AE: The abundance of RNPS1, a protein component of the exon junction complex, can determine the variability in efficiency of the Nonsense Mediated Decay pathway. Nucleic Acids Res 2007, 35:4542-4551.

61. Buffart TE, Tijssen M, El-Bchiri J, Duval A, van de Wiel MA, Ylstra B, Meijer GA Carvalho B: NMD inhibition fails to identify tumour suppressor genes in microsatellite stable gastric cancer cell lines. BMC Med Genomics 2009, 2:39.

62. Kunnev D, Ivanov I, lonov Y: Par-3 partitioning defective 3 homolog (C. elegans) and androgen-induced prostate proliferative shutoff associated protein genes are mutationally inactivated in prostate cancer cells. BMC Cancer 2009, 9:318.

63. Hamaguchi I, Ooka A, Brun A, Richter J, Dahl N, Karlsson S: Gene transfer improves erythroid development in ribosomal protein S19-deficient Diamond-Blackfan anemia. Blood 2002, 100:2724-2731.

doi:10.1186/1471-2407-12-246

Cite this article as: Johnson et al:: The application of nonsense-mediated mRNA decay inhibition to the identification of breast cancer susceptibility genes. BMC Cancer 2012 12:246.

\section{Submit your next manuscript to BioMed Central and take full advantage of:}

- Convenient online submission

- Thorough peer review

- No space constraints or color figure charges

- Immediate publication on acceptance

- Inclusion in PubMed, CAS, Scopus and Google Scholar

- Research which is freely available for redistribution

Submit your manuscript at www.biomedcentral.com/submit 